\title{
I diomas culturais como estratégias populares para enfrentar a violência urbana
}

\author{
Cultural idioms as community strategies \\ against urban violence
}

M ônica N unes 1

1 Instituto de Saúde Coletiva, Universidade Federal da Bahia. Rua Basílio da Gama, $\mathrm{s} / \mathrm{n}, 2 \mathrm{o}$ andar, Campus Universitário, 40110-140, Salvador BA. nunesm@ufba.br
Abstract In the social imaginary, a fairly common idea is that poverty and precarious social conditions develop, among the inhabitants of working-class neighborhoods, violent and criminal behaviors. Every reference to violence, is amplified, overvalued and spread, only perpetuating the monolithic idea that those are the prevailing behaviors. On the other hand, actions that resist violence are significantly less brought to the fore. One of the main objectives of the project Violence and $\mathrm{H}$ ealth: Epidemiological M onitoring, $\mathrm{M}$ emory, Experience and Resistance consisted in identifying community strategies against violence. In this article, we will concentrate on art-and-culture oriented social actions developed for youths by a capoei ra master and on another such activity, proposed by a rastafari leader who developed a "messianic reggae". We will center our analysis on methodological properties of both projects, on their organizational forms and their actuation, on interpretations produced about the violence experienced by such youths, on the cultural idioms and world-views used to contemplate strategies of peace promotion. In the last analysis, we are seeking to identify the "work of culture" which allows, in these projects, an elaboration of conflicts.

Key words Cultural idiom, Social networks, Resistance community strategies, Peace promotion, U rban violence, Popular culture
Resumo É recorrente, no imaginário social, a idéia de que a pobreza e as condições de precariedade social desenvolvem, entre as pessoas dos bairros populares, comportamentos violentos e delinqüentes. Cada referência à violência ou cada indício da mesma é amplificado, supervalorizado e divulgado, perpetuando a idéia única e monolítica de que esses são os comportamentos prevalentes. 0 oposto, ações que resi stem ou que se contrapõem a violências são muito menos evidenciadas. U m dos objetivos centrais do projeto Violência e Saúde: M onitoramento Epidemiológico, M emória, Experiência eResistência consistiu em identificar estratégias populares de enfrentamento da violência. N este artigo, privilegiaremos as ações sociais de cunho artístico-cultural desenvolvidas com jovens por um mestre de capoei ra eaquelas conduzidas por um líder rastafári que pratica um "reaggae messiânico". Centraremos nossa análise nas formas de organização e de atuação de ambos os projetos, em interpretações produzidas pelos mesmos acerca das violências vividas pel os jovens e nos idiomas culturais e cosmovi sões utilizados para contemplar estratégias de promoção da paz. Buscamos identificar o "trabalho da cultura" que permite, nesses projetos, uma elaboração de conflitos.

Palavras-chave I dioma cultural, Redes sociais, Estratégias populares de resistência, Promoção da paz, Violência urbana, Cultura popular 


\section{Introdução}

A violência urbana, dadas as dimensões que atingiu na contemporaneidade, as multiplicidades de formas na qual se manifesta e a complexidade de fatores que estão implicados na sua gênese e perpetuação, tem lançado um desafio que mobiliza estudiosos na sua compreensão e mapeamento. $M$ ais recentemente, os estudos têm se debruçado não apenas sobre 0 entendimento das dinâmicas sociais envolvidas na sua produção, mas também sobre estratégias voltadas para o seu enfrentamento. Sabese que essas intervenções nem sempre são realizadas de forma sistemática e contínua nos diferentes espaços urbanos, apresentando ainda distintas configurações e modalidades.

A escassez de estudos na área da saúde coletiva que focalizem estratégias populares voltadas para a redução da violência pode se dever ao fato de que esses estudos ainda estão excessi vamente centrados sobre ações da sociedade civil organizada, sobre os movimentos sociais e, mais recentemente, sobre os projetos desenvolvidos pelo terceiro setor, ou programas propostos pelo governo para serem realizados com determinados grupos-alvo. M inimizam-se as ações que são desenvolvidas por grupos informais, na sua mai oria fragilizados pela ausência de apoio financeiro, sem visibilidade na mídia, nascidos de experiências cotidianas das pessoas que delas participam. Trata-se de ações que têm a capacidade de se oporem, de forma heteróclita e fragmentada, a certos valores dominantes (M ontero, 1985), ao tempo em que ajudam a proteger ou preservar grupos socialmente mais vulneráveis, como é o caso de jovens em situação de risco.

A pesquisa que originou o presente artigo, intitulada "Violência e saúde: monitoramento epidemiológico, memória, experiência e resistência", situa-se entre aquelas que têm se preocupado em identificar formas culturais ou sociais de resistência à cultura hegemônica ou a condições opressivas da sociedade. I naugurada por Gramsci (1981), essa tradição, que reconhece na cultura popular a presença de certos processos que condensam um potencial transformador, tem sido amplamente explorada no campo da antropologia, que busca identificar esse potencial em ações não necessariamente conscientes ou organizadas (Comaroff, 1985; Scott, 1990).

Para esta análise, tomaremos como objeto o fenômeno da violência urbana e estratégias desenvolvidas para enfrentá-la em um bairro periférico da cidade de Salvador. Dentre as experiências identificadas no bairro estudado, privilegiaremos, neste artigo, as ações sociais de cunho artístico-cultural desenvolvidas com jovens; a primeira delas por um mestre de capoeira em um importante terreiro de Candomblé e com o apoio do Unicef; e a segunda, conduzida por um líder rastafári, que propõe um grupo de "reggae messiânico", sem apoio oficial, mas com expressiva adesão da comunidade. Essas atividades possuem pontos em comum e diferenças que merecem ser descritas pelas suas implicações sociais, culturais e políticas, conformando-se no que podemos chamar de "idiomas culturais".

\section{0 idioma cultural e a resistência popular}

U m idioma cultural refere-se a um conjunto de recursos, mecanismos e significantes que a cultura dispõe/cria de modo a permitir a articulação das experiências individuais e coletivas, produzindo-Ihes sentido e ação concreta (Crapanzano, 1977; O beyesekere, 1990). Essas ações podem estar inscritas: 1) em rituais que fazem um comentário metacrítico da vida social, utilizando-se muitas vezes da vida cotidiana sob a forma de paródia a fim de, pelo humor ou pelo deboche, colocar entre parênteses princípios naturalizados ou práticas essencializadas, que perpetuam estratégias de dominação (I riart, 1998); 2) em modos particulares de uso e simbolização do corpo que redimensionam sua suposta condição de corpo que sofre/padece (páthos), para um corpo que atua na sua condição de corpo experiencial, corpo social e corpo político (Scheper-H ughes \& Lock, 1987); 3) em formas de consciência reveladas pelas histórias de vida que elaboram e ressignificam condições sociais opressivas e de privação e estratégias de sobrevivência e de proteção ou enfrentamento das mesmas ( N unes, 1999; Bozzoli, 1991); 4) na produção de significantes culturais que se revelam como potencialidades de relações dialógicas entre margem e centro de uma sociedade (Corin, 1995) ou se manifestam sob a forma de inversões no que tange à ordem de poderes e valores preestabelecidos (Babcock, 1978).

Essas diferentes formas de ação podem se apresentar de forma combinada, ou isolada, nos diversos grupos socias, evidenciando aspectos da sua história como grupo e da posição 
que ocupam na sociedade. 0 trabal ho antropológico busca explicitar ações dessa natureza e interpretá-las no seu significado social, cultural e histórico-político. Esses diversos fenômenos tradicional mente analisados nos estudos etnográficos - rituais, mitos, narrativas, biografias, obras de arte, etc. - são modos privilegiados de acesso às experiências individuais e coletivas e, conseqüentemente, aos significados produzidos pelos grupos acerca de sua própria história, dinâmica social, sofrimentos, etc. (Bruner, 1986).

Atividades expressas sob a forma de grupos de música, de dança e de luta representam também importantes manifestações culturais que veiculam valores, modos de fazer, representações corporais, etc. A multiplicação de usos dessas atividades sob a forma de programas para jovens com o objetivo de redução dos níveis de violência pressupõe que elas são recursos valiosos na promoção de atitudes solidárias, de valores de respeito ao outro, de desejos de real transformação do meio em que se vive (Castro et al., 2001), configurando uma educação para a pró-sociabilidade (Koller, 1997). No presente trabalho, as atividades desenvolvidas por dois protagonistas sociais serão objeto de estudo e seus idiomas culturais serão submetidos a uma análise hermenêutica de forma a interpretá-los a partir da rede semântica que, no discurso desses dois atores, se remete ao significante violência.

\section{0 trabalho de campo}

A presente pesquisa foi realizada em um bairro periférico de Salvador (BA), em dois momentos contínuos, perfazendo um total de 18 meses de campo. 0 primeiro momento compreendeu a produção de narrativas que envolveram experiências pessoais ou coletivas de situações de violência, além de narrativas que permitiram reconstituir a história oral do bairro, investigando mudanças apontadas pelos moradores do mesmo nas práticas e nos valores ligados à convivência pacífica nos vários contextos de relação interpessoal. 0 segundo momento referiu-se à produção de dados acerca de al gumas agências e instituições que, de forma mais ou menos explícita, atendem pessoas vítimas de violência, construindo eventuais estratégias de proteção ou de redução da mesma. Perpassando esses dois momentos de pesquisa, houve 0 desenvolvimento de uma etnografia que produ- ziu dados relevantes na leitura e compreensão das narrativas e práticas obtidas e observadas ao longo de toda a pesquisa.

O estudo combinou técnicas metodológicas de observação participante, entrevistas semi-estruturadas, grupos focais e histórias de vida. Perfizemos um total de 56 entrevistas gravadas (22 homens e 34 mulheres) de aproximadamente uma hora e meia de duração cada uma. Os dados produzidos foram analisados com 0 auxílio do programa N.U.D.I.S.T. (N-vivo).

A área estudada caracteriza-se por uma precariedade de infra-estrutura, alto índice de desemprego, pela presença de uma associação de bairro fraca e desorganizada e pela ausência de qualquer outro movimento social expressivo, como também de qualquer ação efetiva do poder público na melhoria das condições de vida de seus moradores. As principais ofertas de serviços, bem como de algum tipo de ajuda aos moradores, eram atribuídas quer a igrejas de diversos tipos, quer às organizações de tráfico de drogas.

Com o passar do tempo, identificamos ações sociais com o objetivo de atuarem entre os jovens do bairro desenvolvidas por agências religiosas, grupos de jovens, artistas locais, etc. Dentre essas ações, destacam-se a capoeira, desenvolvida no interior de um terreiro de candomblé, mas aberta à participação de jovens de todo o bairro, e o reggae messiânico, que configura uma banda de música que se apresenta em outros bairros da cidade e que conta com a presença de jovens dançarinas. Essas iniciativas eram descritas por seus líderes como alternativas pedagógicas e culturais, diante da ausência de atividades esportivas, de lazer e artísticas, que buscavam funcionar como possibilidade de inclusão social dos jovens e de construção de uma referência identitária mais positiva no que tange ao seu grupo de pertencimento. Ao mesmo tempo se auto-referiam como um espaço de reflexão e de produção de valores que privilegiassem uma conduta social ética e solidária e de prevenção de situações de risco às quais muitos dos jovens das classes populares estão sujeitos.

\section{A capoeira e o reggae messiânico}

A primeira experiência analisada é realizada por um mestre de capoeira que ensina essa luta a crianças e jovens. Trata-se de uma pessoa extremamente querida por todos os alunos, seus pais e várias outras crianças do bairro que, 
quando ele passa, abordam-Ihe perguntando quando abrirão novas vagas para incorporar mais jovens. A segunda é desenvolvida por um rastafári, que nasceu e reside no bairro. Embora ele inspire desconfiança por parte daqueles que o vêem como um maconheiro, é muito querido por parte dos que o conhecem melhor, inclusive pelos pais das jovens que participam da sua banda de reggae.

U m importante ponto de confluência entre ambas experiências situa-se na sua base religiosa. Enquanto o mestre de capoeira reconhecese como adepto do candomblé, o cantor de reggae diz-se evangélico, além de rastafári. Essas filiações religiosas produzem, no entanto, diferenças na conduta dos dois líderes, pois apenas o segundo apresenta uma atuação proselitista, característica da prática evangélica. Vale dizer que a atitude desse segundo líder parece também condizente com a sua trajetória pessoal de envolvimento em uma vida de transgressões na adolescência. N esse caso, a exigência de conversão trazida pela igreja evangélica associada à filosofia rastafári possibilita, na sua opinião, uma atitude de ruptura dos jovens com "falsos valores", oferecendo-Ihes um norte sólido para reconduzirem a vida.

$\mathrm{N}$ a perspectiva do candomblé, embora essa idéia da "salvação" oferecida pela conversão não esteja presente, há uma ênfase por parte do mestre no aspecto de família presente nessa religião - família de santo, no interior da qual os jovens encontrariam um tecido social de malha estreita (Bott, 1976), um conjunto de regras bem definidas e referenciais identitários que remetem a uma ascendência afro-brasileira valorizada constituindo um eixo de sustentação e de orientação para os jovens, sobretudo para aqueles que vivem situações de fragilidade nos seus laços sociais cotidianos.

Em ambos os projetos, a filosofia religiosa orienta a visão de mundo, os valores e as práticas que, do ponto de vista dos líderes, deveriam ser veiculadas aos jovens. 0 discurso de ambos está fortemente impregnado de críticas à "falta de valores" da sociedade atual e à necessidade de que eles, na relação com os adolescentes, assumam muitas vezes um papel parental, pela ausência, sobretudo, do pai nas famílias contemporâneas, zelando pelo cumprimento de leis que orientem o comportamento dos jovens no sentido de freqüentarem a escola, serem honestos, terem amor próprio, não cultivarem valores e ações violentas. N os seus projetos pedagógicos, eles desenvolvem metodologias e con- teúdos de ensino que buscam estabelecer limites necessários para evitar o risco do desvio ou da transgressão e julgam fundamental sustentar o cumprimento dessas regras em um relacionamento afetuoso, compreensivo e amoroso com os jovens, atitudes que transmitam o real interesse que têm pelo futuro dos mesmos, permitindo-Ihes formular sonhos e projetos de vida.

Embora explicitamente apoiados em um universo religioso, os dois projetos singularizam-se a partir de uma proposta artístico-cultural. No caso do projeto de capoeira, os valores religiosos são reinterpretados a partir do próprio universo dessa luta e de uma linguagem que lhe é particular. Assim, na narrativa do mestre, a linguagem corporal assume proeminência ligando-se a uma história de resistência ancestral desde o tempo dos negros escravos (Araújo, 1997):

Q uando eles chegam aqui, às vezes já chegam pensando mal, aprender pra poder brigar, aquela energia pra poder brigar, quando chega aqui, eu aí já começo a disciplinar, a capoeira não foi criada pra isso, muito pel o contrário, começo a conversar com eles através dos movimentos: "olha, devagar, não é assim; se machucar, você também pode ser machucado, tenha respeito pelo colega". A capoeira não é pra brigar, não foi criada pra brigar, desdequando foi criada, ela foi criada pra se defender dos capitães de mato, dos senhores de engenho na época, por uma necessidade, porque não tinha armas, o negro não tinha arma, ele tinha que desenvolver alguma coisa pra poder se defender, então el e criou aqui na Bahia, no Recôncavo, a Capoeira Angola.(...)

Para o mestre, a capoeira reinsere esses adolescentes em um campo semântico que resgata noções de injustiça e desi gual dade historicamente vividas por pessoas dessa classe social e da raça negra, ao mesmo tempo em que exalta práticas afirmativas na direção de uma conquista de espaços na sociedade pelos mesmos. A principal mensagem é de uma afirmação do grupo, ou desi, pela reflexão, enão pela violência, como se lê abaixo:

a capoeira angola, você tem que ter uma coordenação do corpo ea mente tem que crescer junto, porque, se não, não dá pra você conciliar, certo, nosso intuito aqui não é criar, colocar crianças para andar brigando; muito pelo contrário, é pra não ter que brigar (...).

$\mathrm{O}$ argumento fica mais claro quando ele continua:

aqui a gente passa a filosofia da capoeira, que até... vamos dizer assim, não é igual à do J apão 
nem da China, mas tem o respeito à hierarquia, que nem no candomblé, isso é importantíssimo pra eles, tem essa questão, e também tem outra questão, é os fundamentos; a gente passa os fundamentos dos nossos mestres, alguns já foram, passam pra gente, ea gente vai passando pra eles - por que fazer esse movimento, pra quem não tá fazendo aquele movimento por fazer, cada movimento tem um significado, o canto, cada canto também tem um significado, certo.

A idéia de base é aquela que propõe que a iniciação de crianças e de adolescentes na capoeira significa a inscrição dos mesmos em um universo simbólico (Cruz, 1996) acessado por uma interseção de linguagens (música, movimentos, versos) que tocam os sentidos e o entendimento das pessoas, ou seja, que tem significado coletivo (os fundamentos). 0 idioma da capoeira absorve uma ética que se apóia em valores tradicionais de respeito à hierarquia, ao trabalho, à honestidade, à lealdade, ao mesmo tempo em que incorpora elementos da subjetividade moderna (Csordas, 1994), individualizada e pautada em um idioma de sentimentos (Rosaldo, 1984). Assim, tomando-se a hermenêutica dos cantos da capoeira, tal que realizada pelo mestre e sua assistente, observa-se claramente essa combinação. A capoeira prevê um conjunto de cantos tradicionais dos quais se lança mão de acordo com a pragmática do contexto e prevê também a possibilidade da criação de novos cantos pelos capoeiristas, que traduzam situações e vivências pessoais. Desse modo, contempla-se desde situações sociais até estados psicológicos individuais, em cantos que veiculam desde lições de moral (análogos a parábolas) até aqueles que traduzem sentimentos como o amor e a solidão. N esse sentido, há uma ênfase em um complexo pedagógico de formação dos jovens que implica corpo e mente, em que em ambos o que está em jogo é uma ação comunicativa, um diálogo:

(...) Foi criada pra isso, não pra um capoeirista brigar com outro capoeirista, el es treinavam um com outro através do movimento do corpo, como se estivessem conversando, você faz assim, que eu faço assim, entendeu? E como um diálogo de um com o outro. (M estre)

A capoeira para mim, não é apenas o lance do movimento. A nível mais de cabeça, ela, no meu ponto de vista, ela trabalha muito a minha cabeça, a minha mente. Por exemplo, tem certas si tuações que eu passo dentro do trabalho da capoeira que primeiro eu paro, penso, não uma vez, mas dez vezes antes de agir em determinada si- tuação, então, como diz, é o equilíbrio do corpo e da mente. Então pra mim a capoeira não é só movimento, é o equilíbrio da mente, é saber lidar com determinada pessoa, determinada situação, de como agir, de como retomar, até mesmo a resposta e, ao mesmo tempo, não dar resposta também. (Assistente do mestre)

N ota-se então que a performance dessa luta em toda sua complexidade condensa elementos de identidade cultural, de resistência diante da ameaça de um opressor ao mesmo tempo em que de leal dade e de troca intraclasse (aqui representada pela conversa de corpos). Em uma outra dimensão, ela também é vista como uma superação da dicotomia corpo/mente, em que através da sua prática se acessa seu significado, sendo esse significado que dá equilíbrio ao corpo, quando ele o torna um "corpo sábio". Num terceiro nível, a capoeira funcionaria como um idioma coletivo que orientaria uma prática individual, como um modelo de e para a sociedade (Geertz, 1973). O u seja, existiria na capoeira o exercício de uma aprendizagem para a vida, 0 que associa uma perspectiva filosófico-existencial a uma determinada prática cultural. N esse sentido, observa-se o cuidado de inscrever essa prática no seu contexto histórico de fundação.

No caso da segunda experiência observada, o reggae messiânico, muito do que ela veicula está explícito na imagem do seu líder. A experiência pregressa desse líder e a sua marca identitária de rebeldia e irreverência, aliadas a uma intenção de redenção desse passado por meio de uma participação social ativa, produzem um efeito idiossincrático, comportando alguns paradoxos aparentes.

Quem conhece, de antigamente, quem me viu de pequenininho sabe que eu mudei mesmo, ainda tem pessoas que ainda acha, pela identidade que eu tenho assim, que sou do mal. Eu ando com as crianças aqui que tem gente que fala: "Aquele menino ali é nota 10! Onde passa, as crianças vão atrás dele".

$\mathrm{H}$ oje em dia, Jesus C risto me botou pra eu ficar aqui, você tem que ser radical, amigo, você vai perder muita amizade, tem que ser radical, você quer mostrar que é isso, você tem que ser radical.

Esse líder situa seu discurso em uma crítica social radical, incluindo o questionamento do que ele chama de uma moral hipócrita que não está fundada, do seu ponto de vista, em ideais autênticos e fundamentais.

A maioria dos rastas são pessoas que têm 0 passado parecido com o meu, pelo incrível que pa- 
reça, a galera rastafári já vem de uma pressão, de um problema, então, não éà toa que a gente étão calminho assim, aí a gente vê coi sas que antes a gente... A gente fuma ganja pra tá em contato com Deus, pra tá mais tranqüilo, pô, a gente fuma nesse intuito aí. A gente fica tranqüilo e a gente enxerga coisas que o sistema não quer que a gente enxergue de cara mesmo, com aquela dureza na mente. Eu mesmo, quando ganjo, eu fico tranqüilo, véio, começo a enxergar coisa, faço artesanato, leio a Bíblia com mais aprofundamento.

D efende a filosofia rastafári a partir de uma ética religiosa, presente nos escritos bíblicos. A partir dessa lógica, ele defende o uso da maconha, ressignificada como erva sagrada, a "ganja", a proibição do corte dos cabelos e condena o falso moralismo. Identifica o poder do sistema de camuflar atos inaceitáveis ou condenáveis por trás de aparências. Prega a autenticidade fundamentada na crença, mas se afasta das igrejas (como a evangélica da qual se desligou posteriormente) que, segundo ele, traem os princípios religiosos nos quais ele acredita e que buscam simplesmente enquadrar os seus adeptos por meio do autoritarismo e pela alienação. Recusa a violência, alegando que não precisa agradar aqueles que pautam sua opinião e ação em valores de virilidade manifestados a partir da vingança e da agressão física.

É, portanto, a partir dessa postura hipercrítica que esse líder propõe o seu projeto de ação. Critica a sociedade capitalista e as instituições oficialmente responsáveis pelos jovens, como a escola, que, segundo ele, oferece um ensino alienante, de baixa qualidade e desinteressante, o que Ihes impede de desenvolver uma consciência crítica por não terem acesso, por exemplo, à verdadeira história do País. Esse líder critica ainda duramente e condena uma moral sexual veiculada pela tel evisão que banaliza as relações sexuais experimentadas por adolescentes e que, segundo ele, tornam, sobretudo, as meninas, pessoas mais vulneráveis. 0 projeto preocupa-se em instruir os jovens, através da evangelização, contrapondo-se a valores arraigados como o da agressividade associada à virilidade masculina, mas se preocupa também com a violência à qual os jovens e crianças estão submetidos na sua vida diária, a começar no interior da sua própria casa.

0 projeto do reggae messiânico apóia-se em uma visão que ultrapassa os seus próprios limites, acreditando que a promoção da paz exige mudanças culturais das pessoas que devem ser engendradas nos espaços educacionais por excelência: nas famílias, nas escolas, nas igrejas, entre outros. Articula várias dimensões da realidade que determinam e que previnem a violência, especialmente aquelas que associam identidade pessoal e a identidade coletiva. Entende que o respeito à identidade pessoal e ao direito individual de se exprimir autenticamente a partir das suas crenças esbarra muitas vezes em uma sociedade de valores materialistas, de práticas autoritárias e violentas e onde valores éticos são muitas vezes deixados em segundo plano em nome de falsos moralismos:

É, ele [C risto] dizia que era rebelde, porque eu não quero cair, mais uma vez, na cilada do sistema, do sistema, enten deu? D eixar o cabelo crescer pra eles ver que eu tô me negando mesmo à alma do mundo, entendeu? Essas crianças aí, ói um aí, com brinquinho, tudo bonitinho, passar creminho no cabelo, ficar todo lindo só pra pegar as meninas, desculpe o termo, só de aparência, então eu não posso ficar me escondendo atrás da hipocrisia, tá entendendo? A minha identidade éessa mesma.

A contribuição da filosofia rastafári manifesta-se então pela expressão de valores de autenticidade, de rejeição ao sistema capitalista e de ideais de mudança social (Pinho, 2001), materializados no corpo feito metáfora, portador de símbolos de contracultura: o "maconheiro" e "cabeludo" transformado em mensageiro do sagrado e em porta-voz da real experiência de transformação de uma vida delinqüente, violenta e alienada em uma vida de inclusão e de participação social.

\section{Potencialidades do uso do conceito de idiomas culturais em estudos de práticas sociais de redução de violência}

N os últimos anos, o acúmulo de experiências de intervenção no campo do social, sobretudo aquelas conduzidas pelo terceiro setor, tem ampliado as possibilidades de reflexão em torno do tema da redução da violência. $N$ esse sentido, em países de grande desigualdade social, como o Brasil, destacam-se medidas que produzem impacto sobre as condições de vida da população, mais do que medidas de caráter repressivo. A posta-se especialmente em ações dirigidas aos jovens, sobretudo aqueles de classes populares, que têm sido as maiores vítimas da violência.

Nesse grupo etário, multiplicam-se conceitos e abordagens que tentam dar conta dos 
efeitos positivos dessas variadas medidas de interven ção. Um dos conceitos mais utilizados é o de auto-estima, pretendendo-se que muitas dessas atividades atuam "elevando a auto-estima dos jovens". A auto-estima pode ser entendida como uma auto-avaliação positiva, o sentimento de gostar de si mesmo, permitindo à pessoa orgul har-se de seus empreendimentos, demonstrar suas emoções, respeitar-se, reconhecer os próprios tal entos, investir em seus objetivos (...) (Dupret, 2004). Um segundo conceito trabalha principalmente na perspectiva do "exercício da cidadania" promovido por essas atividades. Pressupõe-se que atividades artísticas, esportivas, etc. podem ser utilizadas como atividades-meio no sentido de despertar nos jovens uma consciência crítica acerca de seus direitos e deveres, além de produzir formas criativas de conquistar a cidadania. Um terceiro conceito, de grande utilidade para entender como jovens que vivem em condições desfavoráveis são capazes de apresentar comportamentos sadios, é o conceito de resiliência. Como o conceito de resiliência traduz-se melhor a partir de uma perspectiva processual (Luthar et al., 2000), combinatória e cumulativa (Yunes \& Szymanski, 2001) e da interação de múltiplos fatores - individual, familiar e do meio (Pesce et al., 2004), a sua compreensão também passa pelo entendimento dos mecanismos pelos quais ações e práticas funcionam na proteção de jovens que vivem situações de risco (H utz et al., 1996).

Extremamente úteis, esses conceitos merecem um exame mais detalhado do seu potencial heurístico para que possa ser evidenciado o campo de atuação de cada um no âmbito de projetos concretos e da forma como interagem entre si. A auto-estima, cidadania e mesmo a resiliência são noções e fenômenos que emergem de histórias e contextos concretos, permeados por valores e pela capacidade humana de produzir significados a partir de campos semânticos compartilhados. Dessa forma, o idioma cultural seria essa matriz a partir da qual se articulariam experiências e práticas no campo social. Para contemplá-lo, dois aspectos são de grande importância: 1) tomar os projetos sociais como objetos etnográficos, dignos de uma descrição densa, explorando-os como comentários sociais (Geertz, 1973), e 2) tomar os atores sociais que os produzem como produtores de significações que imprimem direcionalidade às ações e que afetam (no sentido também de tocar, implicar) as pessoas.
No primeiro aspecto, o que se ressalta é que não se pode tomar projetos sociais presentes no tecido social de forma homogeneizante, sem atentar para as particularidades culturais que Ihes dão profundidade e Ihes atribuem sentidos. Podemos pensar então que, dentro de uma dada cultura, há fenômenos culturais mais significativos que outros, há formas simbólicas mais ricas do que outras e, portanto, a textura ou densidade desses fenômenos teria um impacto sobre o seu efeito transformador ou sobre o seu potencial de acolher as demandas sociais. Um aspecto curioso, por exemplo, é o pressuposto assumido de que toda e qualquer atividade artístico-cultural e de lazer é em si benéfica para os jovens, por aumentar-Ihes a auto-estima e afastá-los dos "perigos da delinqüência", o que nega justamente a pluralidade semântica e ideológica inscrita nessas práticas.

No que tange ao segundo aspecto, acreditase que significados predefinidos mais próximos de universais humanos (respeito, solidariedade, tolerância) têm sido privilegiados nas interpretações de estudos em detrimento de significados atribuídos pel os próprios participantes de um dado projeto e que exprimem valores culturais específicos de determinados grupose suas dinâmicas histórico-políticas subjacentes. Embora os valores universais e aqueles particulares a grupos específicos não sejam incompatíveis, revelando uma ética do humano, a busca de compreender a matriz cultural que os significa e o contexto histórico que os modula é o único caminho de não naturalizá-los, imaginando que podem ser desenvolvidos e estimulados indiscriminadamente em qualquer grupo social. Qualquer manifestação cultural ou prática social que produza um efeito positivo sobre um determinado grupo de pessoas, comunidade, etc., o faz pela rede de sentidos que ela permite construir e pela mobilização de recursos internos ou externos que empoderam essas pessoas no interior de relações sociais concretas (enão abstratas).

Ora, nessa perspectiva, programas sociais que pretendam atuar na redução da violência entre jovens de classes populares podem se revelar ineficazes, caso não se inscrevam nesses efeitos, ou podem ainda funcionar, de modo inverso, apenas como mais uma forma de controle social, atuando de forma ideológica na reprodução de valores hegemônicos e na perpetuação de desigual dades nas condições sociais. A capacidade de monitorar pessoas com recursos que lhes permitam o exercício da cidadania 
e da justiça social, tão necessários para uma reversão de práticas violentas, necessita de práticas que veiculem, enão escondam, os conflitos e as contradições sociais, buscando solução para as mesmas, que permitam a construção de uma identidade coletiva a partir de valores fundamentais inscritos na história dessas pessoas, e que lhes permitam resgatar a dignidade e 0 poder no cerne das relações sociais. $M$ ais do que isso, essas práticas devem ser capazes de reinscrever pessoas em uma filiação, em uma rede de pertencimento na qual elas se reconheçam e na qual elas possam ancorar projetos de futuro.

Desse modo, o efeito protetor de práticas populares para jovens que vivem em situação de violência estrutural alicerça-se numa compreensão fundamental de que estas não se configuram apenas como um passa-tempo para os mesmos, nem têm como objetivo principal retirá-los de uma situação de ociosidade. Não se trata tampouco de através dessas ações simplesmente elevar a auto-estima de jovens socialmente desvalorizados e desqualificados. Trata-se muito mais de uma reinscrição desses jovens em universos de sentido, ou em um campo de significações intersubjetivamente construídas, que reconecta esses jovens com um conjunto de valores, de códigos identitários e de práticas, articulando a experiência dos mesmos e abrindo-Ihes um leque de novas significações e projetos.

N os exemplos deste artigo, as interpretações dessas ações realizadas pelos seus próprios atores descortinam uma gama de sentidos que remetem a situações históricas de discriminação e de exclusão social (dos escravos, dos negros rastafári, dos próprios adolescentes de classes populares), evidenciando ideais de resistência inscritos em práticas. $\mathrm{Na}$ capoeira, observa-se o "fundamento" dessa prática em uma busca de valorização da identidade cultural dos afro-descendentes, na constituição de um espaço de formação de valores e de afetos centrada na idéia de uma família extensiva, um pouco ao modo da família de santo do candomblé, que supre necessidades das famílias de origem ao mesmo tempo em que as apóia. Paralelamente, esse seria um espaço onde se exercitaria uma consciência crítica de situações de injustiça social ao mesmo tempo em que se aprenderiam novas formas de convivialidade e de resolução de conflitos entre pares.

No reggae messiânico, observa-se a confluência de vários desses pressupostos, objeti- vos e metodologias de ação. 0 que muda são os significantes utilizados e as ênfases em certos aspectos mais do que em outros. Assim, a ressignificação do uso da maconha em um contexto cultural específico (da ideologia rastafári) serve como meio de denúncia a atitudes discriminatórias disfarçadas em discursos moralizadores que reificam comportamentos e generalizam significados atribuídos aos mesmos como forma de difundir preconceitos e manter grupos sociais sob suspeita, ampliando-Ihes a situação de marginalidade e exercendo sobre os mesmos um maior controle social (Karlsen S \& Nazroo, 2002). Percebe-se, no líder desse projeto, uma visão crítica acerca de instituições como a escola, a família e a religião que, em se proclamando instituições veiculadoras de valores morais, perpetuam práticas alienantes, empobrecedoras, acríticas, pouco sensíveis às necessidades dos jovens e pouco propícias ao desenvolvimento do potencial criativo e da autonomia e independência dos jovens na qualidade de sujeitos de direito. Incluindo jovens do sexo feminino em um programa artístico que sofre preconceitos da sociedade por ser ligado a uma ideologia de contracultura e de resistência política, ao mesmo tempo em que tem como objetivo estimular valores e comportamentos nas jovens que se contraponham àqueles difundidos pela cultura midiática, cria-se um aparente paradoxo.

É no reconhecimento e desconstrução desse paradoxo que esse líder situa a sua prática. N ão se trata, portanto, de um pressuposto de que é possível passar por cima de contradições e conflitos historicamente construídos em nome de práticas bem intencionadas de educar jovens para uma convivência saudável na sociedade. A reflexão produzida por uma trajetória pessoal caracterizada por uma sucessão de posições marginais é garantia de um acúmulo de experiências de negociação capazes de conformar "espaços de jogos" que permitam às pessoas desses grupos "colocar entre parênteses" os valores centrais (dominantes) da cultura na perspectiva de questioná-los, subvertêlos, flexibilizá-los ou, simplesmente, estabelecer um diálogo entre valores centrais e valores marginais/periféricos da sociedade.

No campo da saúde coletiva, estudos que adotem essa perspectiva podem contribuir na tarefa de identificar práticas culturais socialmente engajadas, embora não necessariamente formatadas em movimentos ou organizações sociais, desenvolvendo um conhecimento espe- 
cializado das "leituras culturais do social", ampliando a noção de participação social a partir da incorporação das "infinitesimais artes de fazer do cotidiano" (de Certeau, 1990), enfatizando o fato de que a redução da violência inscreve-se em combinações de estratégias que assumam tons não conformistas e contra-hegemônicos.

\section{Agradecimentos}

Esta pesquisa contou com a participação de Ronnie Almeida, Carolina H omem, M arília Hughes, M arise M elo e Sílvio Ribeiro, como pesquisadores de campo; e de Jairnilson Silva Paim, como vice-coordenador. Agradeço à valiosa contribuição de todos e ao CN Pq pelo financiamento da pesquisa.

\section{Referências bibliográficas}

Araújo PC 1997. Capoeira - abordagens sócio-antropológicas da luta/jogo da capoeira. M aia. Instituto Superior Série Estudos M onografia.

Babcock B (ed.) 1978. The reversible world: symbolic inversion in art and society. Cornell U niversity Press, Ithaca.

Balestreri R (org.) 1992. Educando para a cidadania. SBAI/CAPEC, Rio Grande do Sul.

Bott E 1976. Família e rede social. Ed. Francisco Alves, Rio de Janeiro.

Bozzoli B 1991. Women of Phokeng: consciousness, life strategy, and migrancy in South Africa, 1900-1983. James Currey Press-H einemann, Portsmouth-Londres.

Bruner EM 1986. Experiences and its expressions, pp. 330. In VW Turner \& EM Bruner (eds.). The anthropology of experience. University of Illinois Press, Urbana.

Castro M M (org.) 2001. Cultivando vidas, desarmando violências: experiências em educação, cultura, lazer, esporte e cidadania com jovens em situação de pobreza. Unesco, Brasília.

Certeau M 1990. L'invention du quotidien. 1'arts de faire. Folio, Paris.
Comaroff J 1985. Body of power, spirit of resistance: the culture and history of a South African people. University of Chicago Press, Chicago.

Corin E 1995. M eaning games at the margins: the cultural centrality of subordinated structures, pp. 173-191. In G Bibeau \& E Corin (eds.). Asceticism and violence in Interpretation. M outon de Gruyter, Berlim.

Crapanzano V 1977. Introduction, pp. 1-39. In V Crapanzano \& V Garrison (eds.). Case studies in spirit possession. John Wiley Press, N ova York.

Cruz AM L 1996. A capoeira eseu jogo de significados. Dissertação de mestrado. Departamento de Sociologia e Antropologia FAFICH, UFM G.

Csordas T 1994. Embodiment and experience: the existential ground of culture and self. Cambridge University Press, Cambridge.

Dupret L 2004. I dentidade e auto- estima: 0 entrelaçamento possível à educação da pós-modernidade. Disponível em <www.ines.org,br/pagina/revista/espaço17/ debatel.pdf >. Acessado em 2/12/2004.

Geertz C 1973. The interpretation of cultures. Basic Books, Nova York.

Gramsci A 1981. Concepção dialética da história. (4ạ ed.). Civilização Brasileira, Rio de Janeiro. 
Hutz C, Koller SH \& Bandeira DR 1996. Resiliência evulnerabilidade em crianças em situação de risco. Coletâneas da AN PEPP 1(12):11-34.

I riart J 1998. Les femmes dans le candomblé: expérience religieuse et idiome de la possession dans la vie des femmes de Cachoeira, Brésil. Tese de doutorado. Université de M ontréal, M ontreal.

Karlsen S \& N azroo JY 2002. Agency and structure: the impact of ethnic identity and racism on the health of ethnic minority people. Sociology of $\mathrm{H}$ ealth \& IIIness 24(1):1-20.

Koller SH 1997. Educação para pró-sociabilidade: uma lição de cidadania? Paidéia FFCLRP-USP, Ribeirão Preto, fev/ago

Luthar SS, Cicchetti D \& Becker B 2000. The construct of resilience: a critical evaluation and guidelines for future work. Child development 71(3):543-562.

M ontero $P$ 1985. Da doença à desordem. A magia na umbanda. Graal, Rio de Janeiro.

N unes M O 1999. À temps e à contre-temps: les voix des tambours du candomblé dans la psychose. Tese de doutorado. Université de M ontréal, M ontreal.
Obeyesekere G 1990. The work of culture: symbolic transformation in psychoanalysis and anthropology. University of Chicago Press, Chicago.

Pesce RP, Assis SG, Santos N \& Oliveira, RVC 2004. Risco e proteção: em busca de um equilíbrio promotor de resiliência. Psicologia 20(2):135-143.

Pinho OSA 2001. Fogo na Babilônia: reggae, black counterculture, and globalization in Brazil, pp. 224-242. In The internationalization of Brazilian music. University of Florida Press, Gainesville.

Rosaldo M 1984. Toward an anthropology of self and feeling, pp. 137-157. In R Shweder \& R Levine (eds). Cultural theory: essays on mind, self and emotion. Cambridge University Press, Cambridge.

Scheper-Hughes N \& Lock M 1987. The mindful body: A prolegomenon to future work in medical anthropology. M edical Anthropology Q uarterly 18(1):6-41.

Scott JC 1990. Domination and the arts of resistance: hidden transcripts. Yale U niversity Press, $\mathrm{N}$ ew $\mathrm{H}$ aven.

Yunes M AM \& Szymanski H 2001. Resiliência: noção, conceitos afins e considerações críticas, pp. 13-42. In J Tavares (org.). Resiliência e educação. Cortez, São Paulo.

Artigo apresentado em 4/10/2004

Aprovado em 11/11/2004

Versão final apresentada em 20/12/2004 